\title{
INFLUENCE OF GROUND GRANULATED BLAST FURNACE SLAG ON PROPERTIES OF CONCRETE PAEMENT
}

\author{
Binod Kumar $^{1}$, L. Sengupta ${ }^{2}$, L. R. Manjuatha ${ }^{3}$ \\ ${ }^{1}$ Pr. Scientist, CSIR-Central Road Research Institute, New Delhi, India \\ ${ }^{2}$ Vice President (TS), JSW Cement Ltd, Mumbai, India \\ ${ }^{3}$ DGM, JSW Cement Ltd, Mumbai, India
}

\begin{abstract}
The influence of using Ground Granulated Blast Furnace Slag (GGBFS) on various properties of Pavement Quality Concrete (PQC) and performance of concrete pavement has been brought out. The amount of GGBFS in PQC mixes was varied from 10 to 60 percent. Workability, compressive strength, flexural strength, abrasion resistance and drying shrinkage of concrete containing GGBFS were evaluated. Significant improvement was observed in strength, abrasion and shrinkage parameters of concrete. The paper concludes that an economical as well as better performing concrete pavement can be constructed by the use of GGBFS in PQC.
\end{abstract}

Keywords: Ground Granulated Blast Furnace Slab (GGBFS), Pavement Quality Concrete (PQC), Concrete Pavement, Flexural strength, Abrasion Resistance, Drying Shrinkage

\section{INTRODUCTION}

Cement concrete pavements are designed on the basis of flexural strength of concrete due to the flexural nature of curling and load induced stresses. It is actually the fatigue strength of the concrete which decides the thickness of the pavement slab to be provided to meet the requirement of design life, traffic, environmental and vehicular loading. Pavement Quality Concrete (PQC), the term usually used in India for the paving concrete must have adequate flexural fatigue strength so that pavement slabs do not undergo bottom-up or top-down transverse cracks due to exhaustion of fatigue strength of concrete before the expiry of its design life which is usually 25-30 years. Other important properties of PQC which influences the performance of concrete pavement are its compressive strength, bearing strength, drying shrinkage, and abrasion resistance. Compressive strength and bearing strength influence the design of joints; drying shrinkage influences the tendency of cracking of concrete as well as the spacing and performance of the joints; abrasion resistance influences the functional performance and riding quality of concrete pavement. Properties of PQC mix play an important role in the overall performance of concrete pavement throughout its life. PQC mixes are designed in such a way that it should not only possesses the required flexural strength to sustain the repeated application of curling and temperature stresses but at the same time it should have adequate compressive strength, less value of drying shrinkage coefficient and high value of abrasion resistance. Though, normally requirement of mix design of PQC is expressed in terms of either Grade of concrete or minimum value of flexural strength or both and workability, but, other properties like drying shrinkage and abrasion resistance should also be evaluated at the time of mix design in laboratory which are very often neglected or taken for granted. The mix design of PQC should be carried out by careful selection and evaluation of various ingredients.

Common and conventional ingredients of $\mathrm{PQC}$ are water, cement, coarse aggregates and fine aggregates. Over the last so many decades, the use of Pozzolanic materials like fly ash, rice husk ash, metakaolin, silica fume, and Ground Granulated Blast Furnace Slag (GGBFS), has been advocated in the concrete for the enhancement of its properties. Out of these Pozolanic materials, fly ash has been widely used in the PQC but use of GGBFS has been very limited despite the fact that GGBFS is a far better Pozzolanic material than fly ash.

Many researchers have investigated theeffect of using GGBFSon compressive strength of mortars and grouts (Dehuai and Zhaoyuan1987, Fonseca et al. 2015). Chloride permeability of concrete with binary and ternary blends containing GGBFS was investigated and found that concrete with GGBFS exhibit lower charge passed and higher compressive strength (Ahmed et al. 2009, Sengul and Tasdemir, 2009). Hogan and Meusal (1981) evaluated the durability and strength development of concrete containing GGBFS and concluded that GGBFS when used to replace 40 to $65 \%$ Portland cement significantly improved the strength, sulphate resistance and alkali aggregate reactivity. 
Microstructure of concrete prepared with cement and GGBFS was studied and it was observed that the partial replacement of Portland cement with GGBFS produced considerable improvement on pores structure, electrical resistivity, carbonation reduction and various other properties of concrete (Divsholi et al. 2014, Marriaga et al. 2011, Oner and Akyuz 2007).

GGBFS is used in cement concrete mixtures in combination with OPC to enhance the short as well as long term strength and durability of concrete. A study was carried out to evaluate the properties of green and hardened concrete prepared with different amount of GGBFS as partial replacement of OPC. This paper contains the results of the study and recommendations for the use of GGBFS in cement concrete mixtures. The influence of using GGBFS on the performance of concrete pavement has been discussed along with the significant enhancement of various properties of PQC.

\section{PROPERTIES OF GGBFS}

In contrast to fly ash (Class F) which contains high amount of silica and very less calcium oxide, GGBFS contains good amount of silica as well as calcium oxide. This makes it a better Pozzolanic material to be used in PQC. Fineness is another important requirement which makes a Pozzolanic material to react fast in Pozzolanic reaction. Lime reactivity and cement reactivity are the overall indicators of the level of Pozzolanicity of the material.

\subsection{Chemical Composition}

The average chemical composition of the slag used in the study is given in Table 1. The GGBFS meets the requirements of IS:12089. It contains good amount of both Calcium Oxide (34\%) and Silica (36\%) which is expected to contribute to both short term and long term strength of concrete.

Table 1: Chemical Composition of GGBFS

\begin{tabular}{|l|l|l|l|}
\hline Sr. No. & Constituent & $\begin{array}{l}\text { Content, } \\
\% \quad \text { by } \\
\text { Mass }\end{array}$ & $\begin{array}{l}\text { Requirements } \\
\text { as per } \\
\text { IS:12089- } \\
1987\end{array}$ \\
\hline 1 & Silica $\left(\mathrm{SiO}_{2}\right)$ & 36.0 & - \\
\hline 2 & Alumina $\left(\mathrm{Al}_{2} \mathrm{O}_{3}\right)$ & 15.7 & - \\
\hline 3 & $\begin{array}{l}\text { Calcium Oxide } \\
(\mathrm{CaO})\end{array}$ & 34.0 & - \\
\hline 4 & Iron Oxide $\left(\mathrm{Fe}_{2} \mathrm{O}_{3}\right)$ & 0.74 & - \\
\hline 5 & Magnesia $(\mathrm{MgO})$ & 9.8 & Max 17\% \\
\hline 6 & Sulphide as Sulphur & 0.40 & Max 2.\% \\
\hline 7 & Manganese Oxide & 0.18 & Max 5.5\% \\
\hline
\end{tabular}

\begin{tabular}{|l|l|l|l|}
\hline 8 & $\begin{array}{l}(\mathrm{CaO}+\mathrm{MgO}+ \\
\left.\mathrm{Al}_{2} \mathrm{O}_{3}\right) / \mathrm{SiO}_{2}\end{array}$ & 1.65 & $\geq 1.0$ \\
\hline 9 & $\mathrm{Glass} \mathrm{Content}$ & 96.8 & $\geq 85 \%$ \\
\hline
\end{tabular}

\subsection{Physical Properties}

Physical properties of GGBFS are given in Table 2. It has got very high value of lime reactivity of $16.2 \mathrm{MPa}$ as against the minimum requirement of 4.5 MPa for any Pozzolanic material. Fraction retained on 45 micron is 7.6 percent which is much less than the specified value of 34 percent as per IS code indicating that it is a very fine material. It should be noted that only the fraction finer than 45 micron of any Pozzolanic material is reactive. Coarser particles do not react and remains as inert filler in the concrete.

Table 2: Physical Properties of GGBFS

\begin{tabular}{|l|l|l|}
\hline S. No. & Property & Test Value \\
\hline 1 & Sp. Gravity & 2.956 \\
\hline 2 & Blaine's Fineness, $\mathrm{m}^{2} / \mathrm{kg}$ & 382 \\
\hline 3 & $\begin{array}{l}\text { Retained on } 45 \mathrm{micron} \text { in } \\
\text { Wet Sieving, } \%\end{array}$ & 7.6 \\
\hline 4 & Lime reactivity, $\mathrm{N} / \mathrm{mm}^{2}$ & 16.2 \\
\hline
\end{tabular}

\section{MIX PROPORTIONS}

PQC mixes were designed with different amount of cement and GGBFS. Mixes were prepared with water-cement ratio of 0.4 and superplasticizer was used for the desired workability. The mix proportions are given in Table 3. Mix S0 designates the proportion with zero amount of slag and prepared with 400 $\mathrm{kg} / \mathrm{m}^{3}$ cement. The mixes S10, S20, S30, S40, S50, S60 represents the mixes in which $10,20,30,40,50,60$ percent cement was replaced by GGBFS respectively. Using these mix proportions, mixes were prepared to cast specimens for testing compressive strength, flexural strength, drying shrinkage, and abrasion resistance. Workability of all the mixes was determined in terms of compaction factor.

Table 3: Mix Proportions

\begin{tabular}{|l|l|l|l|l|l|l|l|}
\hline $\begin{array}{l}\text { Mix } \\
\text { Designation }\end{array}$ & $\begin{array}{l}\text { GGBFS } \\
\text { Replacement }\end{array}$ & $\begin{array}{l}\text { Cement } \\
\left(\mathrm{kg} / \mathrm{m}^{3}\right)\end{array}$ & $\begin{array}{l}\text { Slag } \\
\left(\mathrm{kg} / \mathrm{m}^{3}\right)\end{array}$ & $\begin{array}{l}\text { Sand } \\
\left(\mathrm{kg} / \mathrm{m}^{3}\right)\end{array}$ & $\begin{array}{l}10 \mathrm{~mm} \\
\left(\mathrm{~kg} / \mathrm{m}^{3}\right)\end{array}$ & $\begin{array}{l}20 \mathrm{~mm} \\
\left(\mathrm{~kg} / \mathrm{m}^{3}\right)\end{array}$ & $\begin{array}{l}\text { Water } \\
\left(\mathrm{kg} / \mathrm{m}^{3}\right)\end{array}$ \\
\hline
\end{tabular}




\begin{tabular}{|l|l|l|l|l|l|l|l|}
\hline & Level, $\%$ & & & & & & \\
\hline S0 & 0 & 400 & 0 & 725 & 345 & 805 & 166 \\
\hline S10 & 10 & 360 & 40 & 724 & 344 & 805 & 166 \\
\hline S20 & 20 & 320 & 80 & 723 & 344 & 803 & 166 \\
\hline S30 & 30 & 280 & 120 & 722 & 342 & 802 & 166 \\
\hline S40 & 40 & 240 & 160 & 721 & 343 & 801 & 166 \\
\hline S50 & 50 & 200 & 200 & 720 & 342 & 800 & 166 \\
\hline S60 & 60 & 160 & 240 & 719 & 342 & 799 & 166 \\
\hline
\end{tabular}

\section{RESULTS AND DISCUSSION}

\subsection{Workability}

The PQC must have sufficient workability for the full compaction. The requirement of workability mainly depends upon the method and equipment used for laying the concrete. For manual and fixed-form methods of laying of concrete, the workability should be around $50-60 \mathrm{~mm}$ of slump. The concrete of lesser slum will not be off-loaded from the transit mixture easily at site. If concrete is paved using a fully automatic slip-form paver, the requirement of slump is 15-25 $\mathrm{mm}$. If the concrete has higher slump then edges of the paved concrete pavement may slump down and not able to retain the shape. In terms of compaction factor, the workability of concrete is considered adequate for slip-form paving if the value of compaction factor is between 0.90 and 0.95 . The compacting factor of all the PQC mixes was determined and the values are given in Table 4 . The compaction factor values indicate that there is no adverse impact on the workability of the concrete mix when cement is replaced by GGBFS at all levels. The GGBFS used in the study was observed not increase or decrease the water demand of the mixes. Thus, there is no difficulty in maintaining the water-cement ratio of PQC mixes containing GGBFS.

Table 4: Compaction Factor of GGBFS Concrete

\begin{tabular}{|l|l|l|l|l|l|l|l|}
\hline Mix Designation & S0 & S10 & S20 & S30 & S40 & S50 & S60 \\
\hline Compaction factor & 0.98 & 0.96 & 0.97 & 0.95 & 0.96 & 0.95 & 0.97 \\
\hline
\end{tabular}

\subsection{Compressive Strength}

Compressive strength of all the concrete mixes at 7, 28, and 90 days is given in Table 5. It was observed that the maximum strength of 41.54 MPa at 7 days and $51.35 \mathrm{MPa}$ at 28 days was achieved by S20 mix in which $20 \%$ OPC was replaced by GGBFS. However, maximum long term strength of 61.86 $\mathrm{MPa}$ at 90 days was achieved by $\mathrm{S} 40 \mathrm{mix}$ with $40 \%$ replacement of OPC by GGBFS. The compressive strength of
S50 mix was almost equal to the strength of S0 at all ages indicating that same strength of concrete mix can be achieved by replacing $50 \%$ OPC with GGBFS. Further replacement of OPC by GGBFS beyond $50 \%$ results in the decrease in compressive strength at all ages. Thus, it can be concluded that, though, most optimum replacement of OPC by GGBFS is $40 \%$, but, $50 \%$ OPC can be replaced by GGBFS without compromising the strength requirement of the mix.

Table 5: Compressive Strength of GGBFS Concrete

\begin{tabular}{|l|l|l|l|l|l|l|l|l|}
\hline \multicolumn{2}{|l|}{ Mix Designation } & S0 & S10 & S20 & S30 & S40 & S50 & S60 \\
\hline \multirow{2}{*}{$\begin{array}{l}\text { Compressive } \\
\text { Strength, } \\
\left(\mathrm{N} / \mathrm{mm}^{2}\right)\end{array}$} & 7Day & 31.65 & 32.92 & 41.54 & 34.28 & 32.17 & 29.55 & 27.58 \\
\cline { 2 - 9 } & 28 Day & 46.49 & 48.00 & 51.35 & 49.88 & 47.61 & 46.39 & 38.99 \\
\cline { 2 - 9 } 90 Day/ 28 Day & 90 day & 54.00 & 56.80 & 58.50 & 59.32 & 61.86 & 54.23 & 44.36 \\
\hline
\end{tabular}

\subsubsection{Influence of GGBFS Concrete on Joint Design}

Compressive strength of PQC is used for the design of dowel bars which act as load transfer devices at transverse joint (Photo 1). The load transfer relieves part of the load stresses at edge and corner regions of pavement slab. Whenever a vehicular load passes over the joint, it induces bearing stresses in the concrete surrounding the dowel bar. High bearing stress in concrete can fracture the surrounding concrete leading to the loosening of the dowel bar and deterioration of load transfer system with eventual joint faulting. The length, diameter, and spacing of dowel bars are so designed as to keep the bearing stresses in the surrounding concrete less than the bearing strength of the concrete which is determined using expression given by American Concrete Institute (ACI) 
Committee-225. The bearing strength of the concrete, $F_{b}$, is given by the following expression:

$$
F_{b}=(101.6-b) . f_{c k} / 95.25
$$

Where, ' $b$ 'is the diameter of the dowel in $m m$ andf $f_{c k}$ is the characteristic compressive strength of concrete which is normally $40 \mathrm{MPa}$.

Table 6: Bearing Strength of GGBFS Concrete

\begin{tabular}{|l|l|l|l|l|l|l|l|}
\hline Mix Designation & S0 & S10 & S20 & S30 & S40 & S50 & S60 \\
\hline $\begin{array}{l}90 \quad \text { Day Bearing } \\
\text { Strength, }\left(\mathrm{N} / \mathrm{mm}^{2}\right)\end{array}$ & 39.45 & 41.50 & 42.75 & 43.35 & 45.20 & 39.63 & 32.41 \\
\hline
\end{tabular}

As per IRC:58, dowel bar spacing is determined based upon the 90 days bearing strength of the concrete which is calculated using the above equation by taking 90 days compressive strength. The code recommends that 90 days compressive strength can be taken as 1.2 times the 28 day characteristic strength i.e. M40. In the present study 90 days compressive strength of the conventional concrete mix without GGBFS was observed to be 1.16 times the 28 days strength whereas, for the concrete mix containing 40 percent GGBFS as partial replacement of cement, it was 1.3 times the corresponding 28 day strength.

Higher bearing strength of GGBFS concrete will result in wider designed spacing of dowel bars, thus, reducing the number of dowels at transverse joints. Therefore, with GGBFS concrete economical joint design can be achieved. If
The bearing strength of the concrete increases with the increase in its compressive strength. The bearing strength at 90 days of all the PQC mixes have been determined using the above equation and assuming the dowel diameter as $32 \mathrm{~mm}$. Values are given in Table 6.

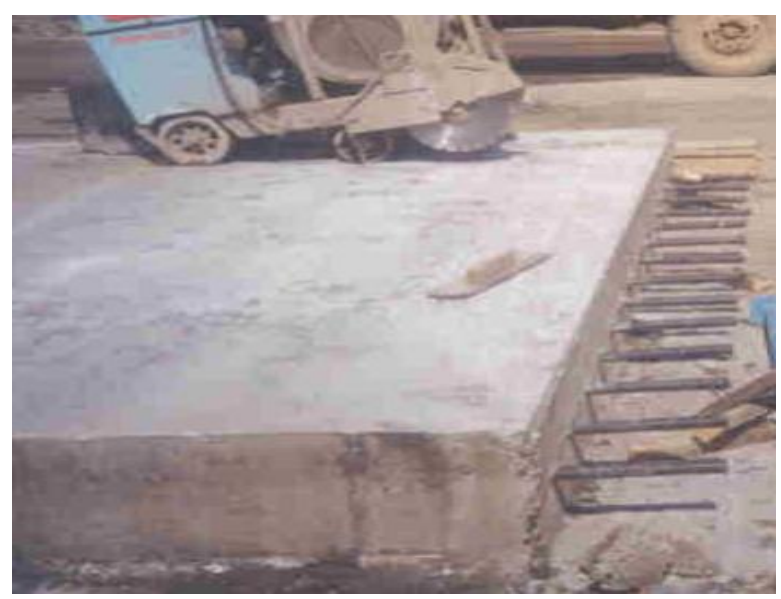

Photo 1: Dowel Bars at Transverse Joint advantage of higher bearing strength of concrete containing GGBFS is not taken by designing economical joints, then, the beneficial effects can be obtained in the perms of better joint performance. Whenever, heavy vehicles pass over the joints, dowel bars induces bearing stress in the surrounding concrete due to which concrete gradually gets crushed into powder under the dowels leading to the loosening of dowels over a period of time. Loosening of dowels creates gradual faulting of the joint. A faulted joint not only increases the roughness but also leads to the breaking of joint edges called 'spalling of joints'. Photo 2 shows the spalling of joints in concrete pavement. GGBFS concrete being stronger in bearing strength will resist crushing of concrete under dowels thereby significantly reducing faulting and spalling of joints and resulting in better performance of joints. Reduction in spalling of joint will also reduce the maintenance needs of the joints.

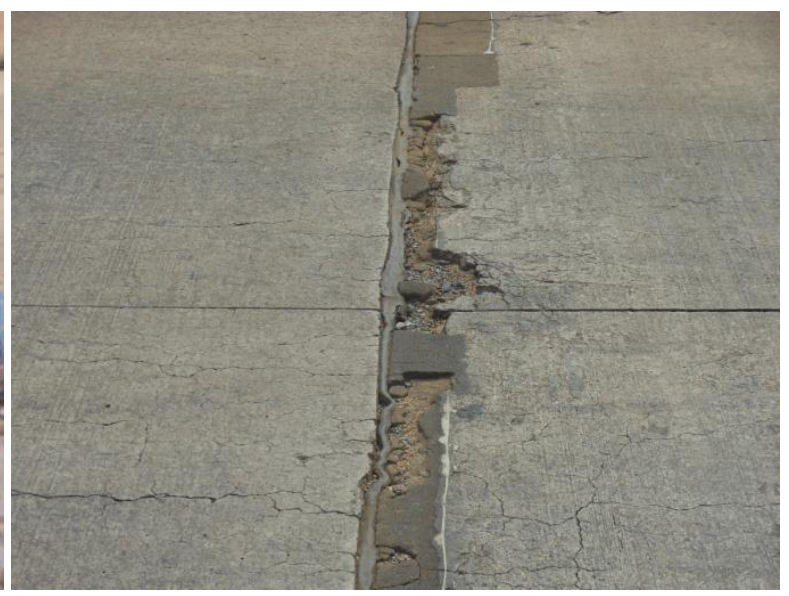

Photo 2: Spalled Transverse Joint

\subsection{Flexural Strength}

Referring to the flexural strength results shown in Table 7, the maximum flexural strength of $4.3 \mathrm{MPa}$ and $5.7 \mathrm{MPa}$ at 7 and 28 days respectively is achieved by S20 mix. But, the maximum 90 days flexural strength of $6.9 \mathrm{MPa}$ is obtained in

case of S40 mix. The flexural strength of S50 mix is almost same as that of control mix S0 at all ages of testing. Further increase in the amount of GGBFS beyond $50 \%$ leads to reduces strength of the concrete at all ages. The results shows that pavement quality concrete (PQC) mixes for the 
construction of concrete roads can be designed with $50 \%$

OPC replaced by GGBFS.

Table 7: Flexural Strength of GGBFS Concrete

\begin{tabular}{|l|l|l|l|l|l|l|l|}
\hline \multicolumn{2}{|l|}{ Mix Designation } & S0 & S10 & S20 & S30 & S40 & S50 \\
\hline \multirow{2}{*}{$\begin{array}{l}\text { Flexural } \\
\text { Strength, } \\
\left(\mathrm{N} / \mathrm{mm}^{2}\right)\end{array}$} & 7Day & 3.5 & 3.7 & 4.3 & 4.1 & 3.9 & 3.6 \\
\cline { 2 - 9 } & 28 Day & 5.2 & 5.3 & 5.7 & 5.6 & 5.5 & 5.3 \\
\cline { 2 - 9 } & 90 day & 5.8 & 6.1 & 6.6 & 6.7 & 6.9 & 5.8 \\
\hline
\end{tabular}

\subsubsection{Influence of GGBFS Concrete on Thickness Design}

Flexural strength of concrete is an important property of concrete as far as the design of concrete pavement is concerned. A concrete pavement has to withstand both vehicular and environmental load during its service life. Both of these loads induce flexural stresses in concrete pavement slab, therefore thickness of slab is designed on the basis of flexural strength of concrete. Higher the flexural strength of concrete lower will be the required thickness of pavement slab to sustain through the design life which is normally 30 years for a concrete pavement.

The design of concrete pavement is carried out on the basis of 90 days flexural strength of concrete as per the provisions of IRC:58. 90 days flexural strength is taken as 1.1 times (10 percent) more than the strength at 28 days. As can be seen from the values of ratio of 90 day to 28 day strength, the increase in flexural strength for concrete containing either no slag (1.12) or $50 \%$ slag (1.09) is around 10 percent as assumed in the design. But, the increase in flexural strength of concrete containing slag from 10 to 40 percent is significantly higher. The maximum increase in strength $(25$ percent $)$ is achieved when 40 percent cement is replaced by GGBFS. This increase in flexural strength will result in significant reduction in designed thickness of concrete pavement.

Thus, if GGBFS is used in PQC at the most optimum level of 40 percent, it will not only reduce the cement consumption but a good amount of reduction in thickness also and thereby producing double advantage for economic construction of concrete pavement. If, advantage of thickness reduction is not taken due to some considerations like the requirement of providing minimum thickness, then the advantage of using
GGBFS can be realized in terms of increased design life of the pavement for the given conditions of traffic and environment.

\subsection{Abrasion Resistance}

Abrasion resistance is extremely important characteristic of the pavement quality concrete used for the construction of concrete roads. Tyres of the moving vehicles create wear and tear at the road surface because of their abrasive action. PQC must have adequate abrasion resistance to resist the abrasive action of vehicle tyres. If PQC do not have required abrasion resistance, then the surface of concrete pavement can be worn out easily under vehicular movement leading to a very rough surface with very poor riding quality (Photo 3 ).

Abrasion resistance of concrete improves generally with the improvement of compressive strength of concrete. It is because of this very important performance parameter that the minimum grade of concrete for the construction of highways is recommended to be M40. A concrete of less than M30 Grade is not considered to fit for the construction of any type of concrete road. As the compressive strength of GGBFS concrete go on increasing up to 40 percent replacement level, its property of abrasion resistance also gets improved.

Abrasion resistance of concrete was determined as per Procedure-A of ASTM Standard C779. In this procedure a revolving -disk machine is used which operates by sliding and scuffing of steel disks in conjunction with abrasive grit (Photo 4). The depth of wear produced on the concrete surfaceis a measure of abrasion resistance of the concrete. Lower the depth of wear, higher the abrasion resistance. Normally a concrete having wear depth less than $0.75 \mathrm{~mm}$ is considered good for concrete pavement for highways and expressways. The depth of wear for all the mixes is given in Table 8 .

Table 8: Depth of Wear for Concrete Surfaces

\begin{tabular}{|l|l|l|l|l|l|l|l|}
\hline Mix Designation & S0 & S10 & S20 & S30 & S40 & S50 & S60 \\
\hline Average Wear Depth, mm & 0.49 & 0.47 & 0.41 & 0.45 & 0.52 & 0.62 & 0.66 \\
\hline
\end{tabular}

The minimum wear depth of $0.41 \mathrm{~mm}$, indicating the maximum abrasion resistance, was observed for $\mathrm{S} 20 \mathrm{mix}$ containing $20 \%$ GGBFS. However the depth of wear for all the concrete mixes was observed to be less than $0.75 \mathrm{~mm}$ which is generally required for PQC. Thus, GGBFS concrete 
has better capabilities to resist wear and tear of vehicle tyres as

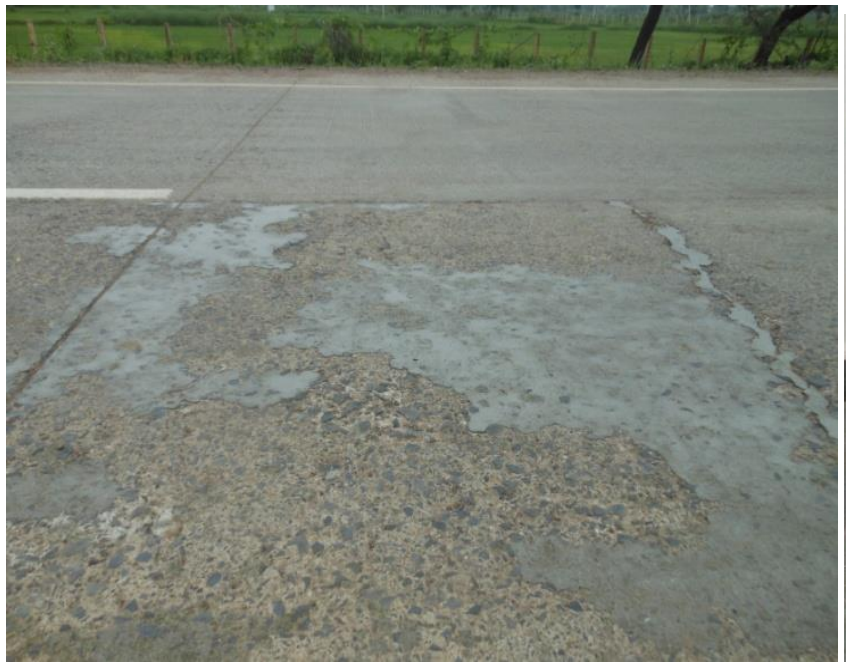

Photo 3: Abraded Concrete Surface

\subsection{Drying Shrinkage}

Drying shrinkage of concrete indicates the amount of shortening of dimensions of concrete pavement slabs when it undergoes drying process under environmental conditions. It affects the aggregate interlocking which exists in transverse and longitudinal joints and cracks. Aggregate interlocking helps load transfer across the joint and crack whenever wheels of the vehicle pass over them. Drying shrinkage also indicate the potential for development of shrinkage cracks on the concrete surface during and after laying. Thus, a lesser value of drying shrinkage is always desirable for PQC mixes to compared to the normal concrete.

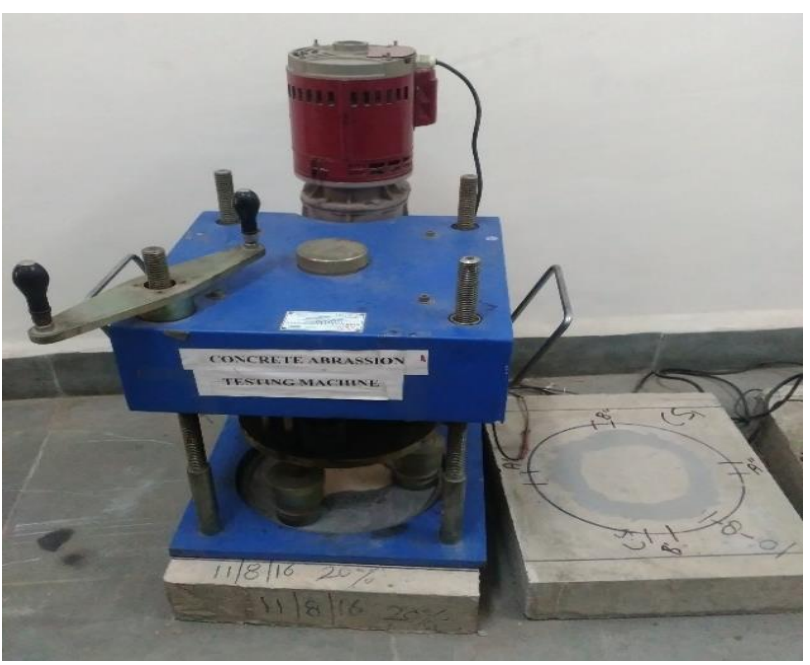

Photo 4: Tested Sample of S20 Mix

maintain higher level of aggregate interlocking at joints of concrete pavement and also to avoid shrinkage cracking.

Drying shrinkage values of GGBFS concrete are given in Table 9. The drying shrinkage of the concrete decreases with increase of GGBFS content. Maximum value of 596 microstrain and minimum value of 232 microstrain was observed for S0 and S60 mixes respectively. Thus, GGBFS concrete has lower value of drying shrinkage which is desirable for better performance of concrete pavements.

Table 11: Drying Shrinkage of Concrete Mixes

\begin{tabular}{|l|l|l|l|l|l|l|l|}
\hline Mix Designation & S0 & S10 & S20 & S30 & S40 & S50 & S60 \\
\hline Drying Shrinkage, $\mu \varepsilon$ & 596 & 584 & 430 & 382 & 292 & 286 & 232 \\
\hline
\end{tabular}

\section{CONCLUSION}

The following conclusions can be drawn from the analysis of the results of various properties of GGBFS concrete:

- The use of GGBFS do not have any adverse effect on the workability of pavement quality concrete. Any small variation in the workability at site can be dealt with by varying dose of super plasticizer.

- $\quad$ Both short term (7 \& 28 days) and long term (90 days) compressive of concrete is increased when cement is partially replaced by GGBFS up to a level of $40 \%$. When $50 \%$ cement is replaced by GGBFS, the strength of the concrete remains almost same. The increase in compressive strength will result in economical and better performing joint design.
- $\quad$ The increase in both short and long term flexural strength of GGBFS concrete can give an economical designed thickness of concrete pavement. The advantage of increased flexural strength can also be realized longer design period of GGBFS concrete pavement.

- Abrasion resistance of GGBFS concrete has been observed to be better than normal PQC. This can help maintaining the surface texture for a longer period of time.

- Drying shrinkage of concrete reduces with the increase in GGBFS content. Reduction in drying shrinkage will result in better aggregate interlocking at joints and cracks of concrete pavement. It will also reduce the tendency of shrinkage cracking in concrete pavement slabs. 
- $\quad$ Thus, concrete containing GGBFS is comparatively more suitable than conventional PQC for road construction

\section{ACKNOWLEDGEMENTS}

The authors are thankful to the Director, Central Road Research Institute (CRRI), New Delhi, India, for permitting the publication of this paper.

\section{REFERENCES}

[1] IRC:58, 'Guidelines for the Design of Plain Jointed Rigid Pavements for Highways".

[2] Ahmed, M. S., Kayali, O., and Anderson, W., 2009. Evaluation of Binary and Ternary Blends of Pozzolanic Materials Using the Rapid Chloride Permeability Test. Journal of Materials in Civil Engineering, ASCE, Vol.21, No.9, pp. 446-453.

[3] Dehuai, W. And Zhaoyuan, C., 1997. On Predicting Compressive Strengths of Mortars with Ternary Blends of Cement, GGBFS and Fly Ash.Cement and Concrete Research, Vol.27, No.4, pp.487-493.

[4] Divsholi, B. S., Lim, T. Y. D., and Teng, S., 2014. Durability Properties and Microstructure of Ground Granulated Blast furnace Slag Cement Concrete.International Journal of Concrete Structures and Materials, Vol. 8, No. 2, pp. 157-164.

[5] Fonseca, F. S., Godfrey, R. C., and Siggard, K., 2015. Compressive Strength of Masonry Grout Containing High Amounts of Class F Fly ash and Ground Granulated Blast Furnace Slag.Construction and building Materials, Vol. 94, pp. 719-727.

[6] Hogan, F. J., and Meusal, J. W., 1081. Evaluation for Durability and Strength Development of a Ground Granulated Blast Furnace Slag. Cement, Concrete, and Aggregates, CCAGDP, Vol. 3, No.1, pp. 40-52.

[7] Marriaga, J. L., Claisse, P., and Ganjian, E., 2011. Effect of Steel Slag and Portland Cement in the Rate of Hydration and Strength of Blast Furnace Slag Paste. Journal of Materials in Civil Engineering, ASCE, Vol.23, No.2, pp. 153-160.

[8] Oner, A. And Akyuz, S., 2007.An Experimental Study on Optimum Usage of GGBFS for the Compressive Strength of Concrete. Cement \& Concrete Composites, Vol. 29, pp. 505-514.

[9] Sengul, O. and Tasdemir, M. A., 2009. Compressive Strength and Rapid Chloride Permeability of Concrete with Ground Fly Ash and Slag.Journal of Materials in Civil Engineering, ASCE, Vol.21, No.9, pp. 494-501. 